\section{[LIGERO] MANUAL ILUSTRADO PARA PROYECTAR UNA VIVIENDA DEL SIGLO XXI ISEGÚN LOS PRINCIPIOS DEL ARQUITECTO CONTEMPORÁNEO PROMEDIO]}

ISRAEL ROMERO ÁLAMO

EDITORIAL LA CHIMENEA, CHIMBOTE-PERÚ, 2013

RESEÑA DE JOAN FELIU FRANCH

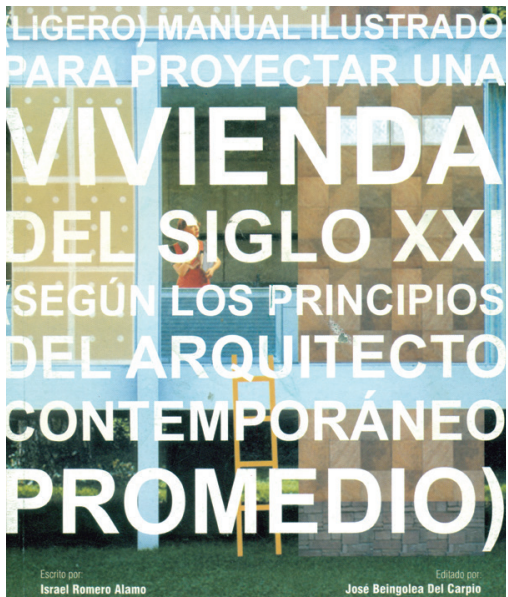

"Hay que ser absolutamente moderno", dicen que afirmó muy lúcidamente Jean Arthur Rimbaud, padre de la poesía moderna y participante en ese primer ensayo de autogobierno obrero que fue la Comuna de París (aunque me parece que Rimbaud nunca participó en la Comuna de París, eso sí, inspirado por ella escribió algunos poemas. Se dice que estuvo semanas antes de los hechos y que fue violado por unos soldados cuando tenía 17 años, pero hay veces que la realidad no conviene a la historia).

La cita de Rimbaud me sirve para introducir el libro (Ligero) $\mathrm{Ma}$ nual ilustrado para proyectar una vivienda del siglo XXI (según los principios del arquitecto contemporáneo promedio) escrito por Israel Romero Álamo, editado por José Beingolea del Carpio, y diagramado por Vivian López Vallejos; una publicación de La Chimenea (Chimbote, 2013). Y citaba a Rimbaud porque el libro de Romero es de gran modernidad (la maquetación de Vivian López tam- bién es excepcional) porque trata con gran ironía la realidad de la arquitectura mayoritaria no solo en Perú, sino en gran parte del mundo. La paradoja, y de ahí la importancia y necesidad del estudio, es que mientras las obras de viviendas para la clase media son innumerables en todas las ciudades del país, no existen casi investigaciones sobre la arquitectura de la vivienda para la llamada clase media.

Es la de la clase media una categoría discutida, porque casi todos nos sentimos clase media. Prueben hacer el ejercicio. Pregunten en su trabajo con qué clase social se identifican sus amigos y compañeros. Pregunten a sus subordinados y a sus jefes. A secretarias, secretarios y gerentes. Lo más seguro es que lleguen a la misma conclusión que yo: todos se sienten clase media.

Es lógico, por tanto, que el volumen constructivo más importante en las ciudades esté formado por las reformas y las viviendas que la población de clase media muchas veces hace por su cuenta, sin asesoramiento profesional. Sin embargo, es un campo invisible para los gobiernos y para las instituciones de los arquitectos, incluyendo las facultades de arquitectura que, salvo escasas excepciones, están completamente al margen de este fenómeno. De hecho, una cátedra tipo arquitectos de familia no existe en ninguna facultad. Entre el dolor y los medicamentos está el médico. Entre los materiales y el que necesita construir su casa, debería estar el arquitecto de clase media. Lo que sucede es que el arquitecto aspira (legítimamente) a pertenecer a la élite de la arquitectura y hacer grandes obras, y no está interesado en una construcción que seguramente acabará alterada por las necesidades y gustos de la dueña de la casa, en cooperación con el constructor.

En resumen, un mundo de paradojas que constituyen la realidad, descrita con precisión quirúrgica y lenguaje culto e irónico. 


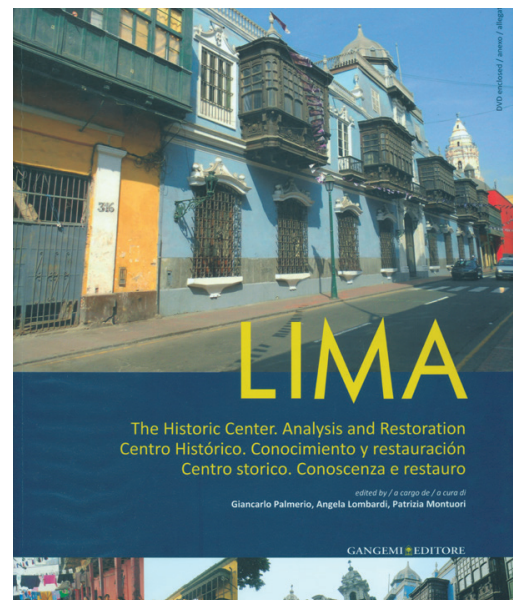

Hablar de este libro exige e invoca referirse al núcleo urbano fundacional de la ciudad que hoy conocemos como Lima, el cual resulta patrimonio cultural de la nación peruana de un interés tan grande que ha permitido que buena parte de él se inscriba en la lista del $\mathrm{Pa}$ trimonio Cultural de la Humanidad por Unesco. Sin embargo, dicho Centro Histórico se encuentra en condiciones muy degradadas de conservación, amenazado por las presiones económicas de gran escala y, por ende, muy urgido de una potente y sostenible acción de recuperación y puesta en valor social. Este libro, publicado en virtud al significativo apoyo de la World Monuments Fund, presenta un método de estudio y aproximación implementado entre 2009 y 2011 gracias a una serie de investigaciones desarrolladas en conjunto entre la Facultad de Arquitectura de la Universitá Sapienza di Roma y la Facultad de Arquitectura, Urbanismo y Artes de la Universidad Nacional de Ingeniería (FAUAUNI) de Lima, Perú, cuyo objetivo fue reconocer el patrimonio arquitectónico y urbano en peligro de desaparición y colapso previo a las

\title{
LIMA. CENTRO HISTÓRICO. CONOCIMIENTO Y RESTAURACIÓN
}

\author{
GIANCARLO PALMERIO, ANGELA LOMBARDI, PATRIZIA MONTUORI [EDITORES] \\ GANGEMI EDITORE, ROMA-ITALIA, 2012
}

RESEÑA DE JOSÉ HAYAKAWA CASAS

posibles intervenciones a emprender para su recuperación sostenible y puesta en valor social y contemporánea.

Este libro posee una sección introductoria donde se desarrolla con cierta profundidad aspectos como el liderazgo mundial en pro de la investigación y conservación del patrimonio arquitectónico de la Universitá Sapienza di Roma, el tipo de formación especializada que necesita la preservación del Centro Histórico de Lima, las características que ameritan el reconocimiento de Lima como $\mathrm{Pa}$ trimonio Mundial, el accionar de la World Monuments Fund y el balance preliminar de esta investigación interuniversitaria

La primera parte de esta publicación nos presenta de una forma sintética, pero profunda, los trascendentales antecedentes precolombinos de la Comarca de Lima, la historia de la Ciudad de Los Reyes y su fundación por parte de los españoles, la evolución y aportes de los siglos XIX y XX y su Estado actual de conservación y deterioro. Sus aportes son dignos de resaltar, gracias al magnífico soporte que brindan documentos inéditos, huellas y vestigios edificados de lo más antiguos, indudablemente merecedores de una sostenible protección para que puedan lograr ser transmitidos de generación a generación. La segunda parte trata el tema de la conservación del Centro Histórico de Lima y los fundamentos teóricos y metodológicos para la restauración de centros históricos, a partir de un análisis del patrimonio en peligro. Aquí destaca el balance histórico que aporta el Arq. Víctor Pimentel acerca de los últimos 90 años de recuperación monumental en Lima y la examinación de ciertos casos de análisis arquitectónico en el Centro Histórico de Lima, desarrollado por Ángela Lombardi y Patrizia Montuori. La tercera y última parte analiza las técnicas de construcción locales más difundidas en Lima y los métodos de restauración compatibles a dichas técnicas constructivas tradicionales, y se concluye con la intervención de recuperación realizada en la Casa de las Columnas, promovida por el World Monument Fund, a manera de caso emblemático y replicable. 


\section{ESTUDIO TIPOLÓGICO DE LA VIVIENDA TACNEÑA}

\author{
LUIS MONTENEGRO VARGAS \\ COLEGIO DE ARQUITECTOS DEL PERÚ-reGIONAL TACNA, PERÚ, 2010
}

RESEÑA DE JOSÉ HAYAKAWA CASAS

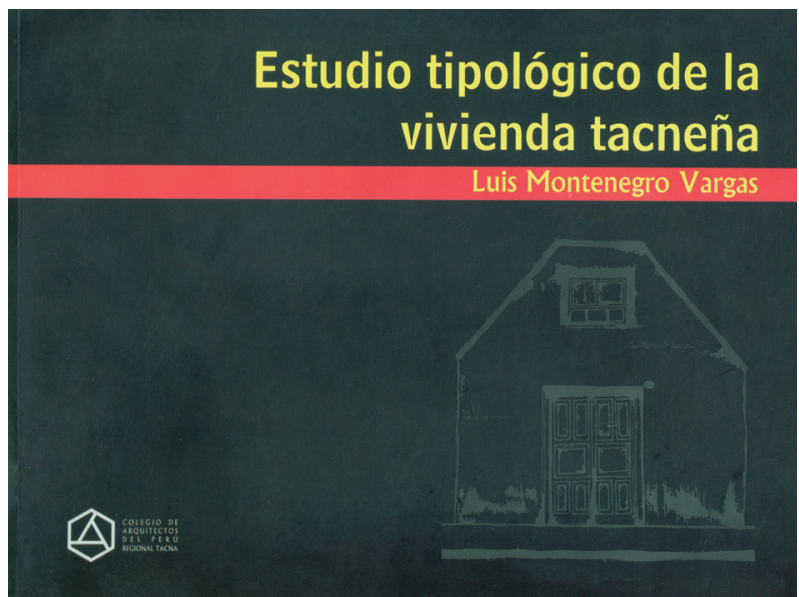

Nos aproximamos a un breve libro que, mas allá de su carácter sintético, posee aspiraciones fundacionales en el ámbito del conocimiento de la vivienda tacneña, en el marco mayor de la vivienda tradicional del Sur peruano. De hecho, el gran investigador de la arquitectura vernácula peruana, Arq. Jorge Burga Bartra, mencionaba entre los principales méritos de esta publicación:

\footnotetext{
"Primero, es un digno esfuerzo por valorizar y preservar la interesante arquitectura tradicional de Tacna a partir de sus característicos techos de mojinete truncado. Segundo: Este esfuerzo cubre un lugar en el discurso pendiente de información sobre la arquitectura peruana. Tercero: Este es un producto de una nueva generación de arquitectos que despliega una visión regional distante y que supera el centralismo limeño".
}

El autor abraza con mucha convicción y utiliza como pie forzado la idea de reconocer en Tacna a uno de los espacios mas privilegiados para comprender la historia del Perú, desde su historia regional sur y con especial énfasis entre la segunda mitad del S.XIX -en el lapso anterior a la Guerra del Pacífico- y la primera mitad del S.XX -finalización del Oncenio de Leguía-. Ergo, estudiar la evolución de la vivienda tacneña nos permitirá (re)conocernos como colectivo a partir de nuestras posibilidades y/o limitaciones, de nuestros factores internos y/o influencias, de nuestras preferencias e ideas... Y con mucha más razón, cuando nos percatamos de la utilización del método de análisis tipológico, el cual insistirá en identificar, analizar y divulgar. Precisamente, el enfoque -y "reconstrucción"- de los tipos edilicios demandó el relevamiento y análisis in situ de las referidas viviendas y ello permitió, a su vez, la determinación de sus características formales, espaciales y estilísticas para definir finalmente los tipos de vivienda urbana.

El libro posee cuatro capítulos: el primero denominado "Generalidades", donde el autor explicita sintéticamente el objetivo, el ámbito de estudio, el marco teórico al cual se adscribe -enfatizando nociones como "tipología", "tipo", "prototipo", "modelo”, “arquetipo”, "vivienda", "ciudad”, "Zona Monumental"-, los alcances históricos urbanos. El Capítulo II titulado "Estudio comparativo por vivienda” se explaya generosamente en la comparación de la Concepción original versus sus situación actual, en las 12 casuísticas identificadas (tipo Cuarto-siglo XIX, tipo Cuarto con corredor-siglo XIX, tipo Cuartos con corredor central-siglo XIX, tipo Cuartos agrupados-siglo XIX, tipo Cuartos 02 niveles-siglo XIX, tipo Vivienda popular-siglo XIX-XX, tipo Casa Colonial 01 nivel-siglo XIX, tipo Casa Colonial 02 niveles-siglo XIX, tipo Casa Republicana 01 nivel-siglo XIXXX, tipo Casa Republicana 02 niveles-siglo XIX, tipo Casa Quinta 01 nivel-siglo XIX-XX, tipo Casa Quinta 02 niveles-siglo XIX-XX). El tercer capítulo denominado "Propuestas y conclusiones", aborda temas como la evolución tipológica, una propuesta y una categorización tipológica, para finalmente lanzarse a establecer como conclusiones, los tipos edilicios identificados de la vivienda tacneña. El cuarto y último capítulo evidencia la bibliografía utilizada y los anexos explicitan la categorización tipológica. Como colofón, es destacable mencionar que el "mapeo" de las viviendas estudiadas brinda a este libro un potencial turístico importante al fungir como una utilísima y experta guía de arquitectura local. 


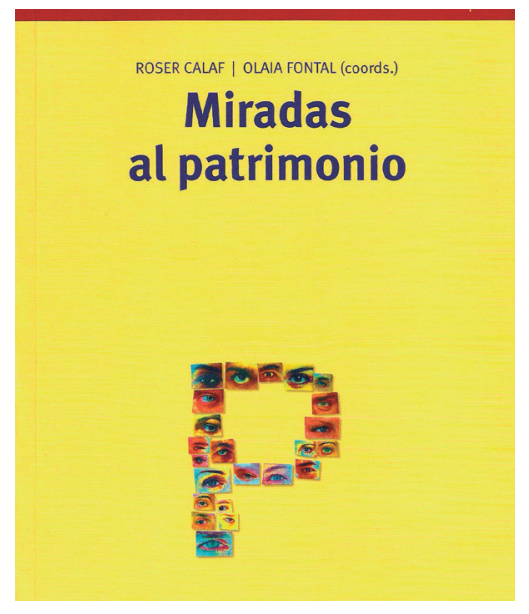

Es un libro eminentemente didáctico desde su estructura. El collage de proyectos/artículos conducen por el mundo del conocimiento teórico del patrimonio cultural y proyectos vivenciales en ámbitos patrimoniales. Este collage permite al lector aportar su particular mirar del patrimonio.

Los objetivos planteados para la compilación de las diferentes narrativas teóricas y aquellas que hemos denominado vivenciales han sido cumplidos ampliamente y es importante reproducirlos para valorar el carácter pedagógico del libro.

Abordar el patrimonio desde una perspectiva educativa en contextos formales, no formales e informales.

Plantear criterios teóricos desde la óptica de la educación y, concretamente, desde el punto de mira de quienes trabajamos en la formación de maestros y que en el ámbito académico se reconocen con la denominación de didácticas específicas.

Conocer diferentes modalidades de intervención sobre el patrimonio, tanto en el ámbito internacional como el caso local de Asturias y otras regiones del país.

Analizar interpretaciones que sobre el patrimonio realizan diversos profesionales en espacios nacionales e internacionales y comprobar cómo las miradas que aportan resultan complementarias.

Evidenciar la importancia de patrimonios emergentes, como el industrial, el geológico o la producción

\title{
MIRADAS AL PATRIMONIO
}

\author{
OLAIA FONTAL MERILLAS, ROSER CALAF MASACHS (COORDS.) \\ EDICIONES TREA, GIJÓN-ESPAÑA, 2006
}

\author{
RESEÑA POR INÉS DEL ÁGUILA RÍOS
}

artística en la Red, patrimonios que irrumpen con fuerza y aportan nuevas peculiaridades para los ámbitos más consolidados, como los que se hallan dentro de la denominación tradicional de patrimonio cultural.

El libro tiene dos entradas que el lector puede escoger, para MIRAR el patrimonio como se señala en el prólogo de la obra, entendiendo el MIRAR como

“...todo aquello que ayuda a conformar identidades, caracteriza contextos, genera sentimientos de apropiación y pertenencia, pertenece a una sociedad que es al tiempo su directa legataria y se va modificando en función de las miradas que sobre al se proyecten en cada momento".

La primera parte del libro contiene artículos que se unen y forman una red educadora del proceso que demanda pensar y comunicar el concepto de patrimonio. La segunda parte es una red de artículos que en términos generales son fuentes primarias que sustentan la idea que la valoración del patrimonio demanda crear colectivos que desde diferentes miradas construyan la mirada global de valoración del patrimonio. Un ejemplo de esta mirada global es la declaración de Macchu Pichu como patrimonio universal en el que un coro de voces afectivas y miradas interdisciplinarias educadoras conformó esta valoración.

En la primera parte, el artículo cruzar miradas, tiene especial im- portancia el concepto de currículo, entendido como construcción social y como instrumento de comunicación entre la teoría y la práctica, y como instrumento pedagógico para conducir el juego entre alumnos y profesores. En general, en esta parte se plantean temas metodológicos para conducir la enseñanza sobre el patrimonio, especialmente la relación escuela/patrimonio.

La segunda parte del libro mantiene la mirada educadora y desde la investigación-acción nos prueba que las voces aisladas no son señas del patrimonio y que un coro de voces suena con importantes efectos educativos. La lectura de esta parte es un viaje hacia los diferentes mundos del patrimonio que la mirada interdisciplinar del geográfo, del museólogo, del gestor en turismo, del planificador, etc., facilitan el disfrute del paisaje natural, del paisaje urbano, de los puertos, de la ciudad que en su conjunto nos introducen en dichos mundos imaginando $y$ creando valoraciones de dichos patrimonios. Es motivador como la lectura cromática de la ciudad añade un elemento vital para valorar el patrimonio, recuperar las escuelas rurales otorga calidez a las metodologías patrimoniales. El descubrimiento del paisaje industrial con sus retos museológicos y museográficos insta miradas para entender su historia y significado en el presente y su inserción en los mundos del patrimonio. 